A

research data management (RDM) has grown into an increasingly familiar service activity in academic libraries, there remains a knowledge gap for liaison and subject librarians attempting to take on these additional responsibilities. As one option to address this, the authors were contracted by ACRL to create a new full-day workshop targeting this specific audience. The result is the ACRL RoadShow, Building Your Research Data Management Toolkit: Integrating RDM into Your Liaison Work. Now in its second year, the RDM RoadShow has traveled extensively in the United States as well as one international trip and continues to assist in meeting the foundational RDM educational needs for liaison librarians and to identify where further education is desired.

\section{Designing the road show}

In Spring 2016, we began the curricular development process with the stated goals of providing foundational understanding of RDM as well as creating resources and tools that could be immediately implemented in daily practice as librarians teach and collaborate with students and faculty researchers. We used backwards design, based upon the work of Grant Wiggins and Jay McTighe, ${ }^{1}$ deriving the courses and educational materials logically from the intended results. Our results were first articulated as learning objectives, then as the means of measuring whether the objectives has been achieved, and finally the education materials were derived from the learning objectives.

The learning objectives for the RDM Road Show are:

1. Participants will identify data within the research process and lifecycle in order to articulate the role of the libraries in the management of data to researchers.

2. Participants will learn how to develop expertise in the nuances of disciplinary requirements for data management in order to educate their faculty and students about data best practices for their discipline.

3. Participants will articulate specific existing skills that they already possess as librarians, which transfer to data services in order to begin building a toolkit of research data management skills.

4. Participants will identify campus partners in research data management in order to create an environment of research data management support for their faculty.

5. Participants will articulate the parts of a data management plan in order to describe its role as a living document within a research project.

Abigail Goben is information services librarian at the University of Illinois-Chicago, email: agoben@uic.edu, and Megan Sapp Nelson is professor of library sciences at Purdue University, email: msn@purdue.edu

(C) 2018 Abigail Goben and Megan Sapp Nelson 
6. Participants will apply their relevant prior knowledge of their disciplines to create a research data management interview plan in order to facilitate faculty engagement.

The session topics integrated within the one-day workshop include:

- An Overview of RDM,

- Applying Your Liaison Skills,

- Learning to Serve Your Discipline's Needs,

- Planning for Data Management, and

- Developing Campus Partners and Collaborations

Each session has a slide deck that the presenters use to introduce the content. The majority of the workshop, however, relies heavily on interactive group and individual learning activities completed by participants at each location. Activities include audience response polls, brainstorming with small groups, assessing personal library skills and their relation to data management activities, and creating an elevator pitch for a campus collaborator. Many of these activities include selective reporting to the attendee group as a whole or sharing with peer participants. These identifiable and anonymous sharing opportunities allow for immediate clarification if participants are struggling with any specific topic as well as generating regional expertise and yielding library colleagues for collaboration.

Throughout the day, participants change tables and collaborators. This engages different kinds of knowledge skill sets and-in the case of multi-institution events-introduces colleagues across institutions or specializations, which has been a specific request of several hosts.

The handouts and other materials used throughout the day provide opportunities for participants to assess their own knowledge while identifying how they want to engage with researchers after the workshop. The slides and handouts are available on the ACRL Scholarly Communication Toolkit under the Research Data Management tab ${ }^{2}$ and come with a CC-BY-NC 4.0 license as we anticipate and encourage frequent reuse.
Two presenters attend each workshop, drawing from a pool of six. The presenters are a combination of data librarians and liaison librarians who have a significant data component to their jobs. In addition to teaching the prepared curriculum, the presenters have many opportunities to provide relatable insight and their own personal experiences, successes, and struggles with participants. By changing the teams for each road show, the presenters get to engage with the curriculum in new ways and learn from each other which examples or personal customizations seem to work best. Following each road show, the presenters debrief with the whole team, suggesting and discussing minor changes to the curriculum. This process has brought about iterative changes to the curriculum, primarily based upon participant feedback.

\section{The first year of road show}

In the first year that the RDM RoadShow was launched, ten sites have hosted the event, with more than 450 attendees participating thus far. Two regions of the National Network of the Library of Medicine hosted events and our first international event was at the University of the West Indies in Trinidad and Tobago in November 2017. Average attendance is 50 to 75 , and most events are hosted by a consortium of institutions.

Participants have brought a wide variety of expertise to the RDM RoadShow, both across the library and institution as well as with research data management. In addition to liaison librarians attending, participants regularly include metadata and digital services librarians, special collections librarians and archivists, and administrators interested in expanding support and capacity. Several sites additionally invited colleagues from across campus. Participants from research offices, high performance computing centers, clinical and translational centers, and IT offices have also attended the RDM RoadShow.

The pre-survey responses indicated that the respondents were evenly split among those who were not confident that they had the skills, knowledge, and training to 
provide research data management services and those who felt that they did have the necessary skills in place. One month after attending the R D M R o a d $\mathrm{S}$ h O w , $66 \%$ of respondents indicated that they felt that they had the nece s s a ry skills in place, an increase of $16 \%$ in self-re-

Pre-survey responses: As a librarian, I have the skills, knowledgeand training to provide RDM services.

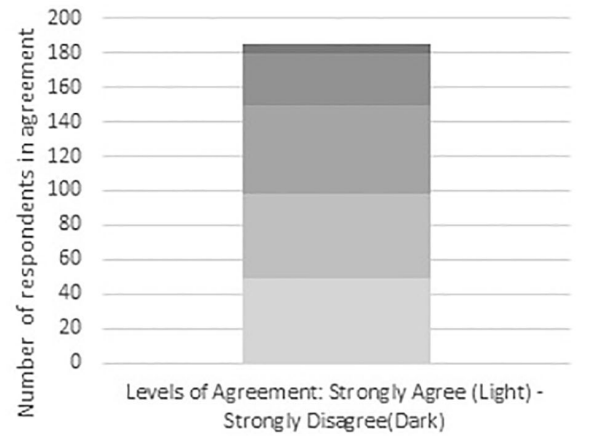

The pre-event survey is shared with the presenters just prior to the event in order to help them understand the assigned job de- ported readiness on the part of respondents (see figures 1 and 2).

\section{Road show: The research project}

In addition to being an educational oppor- scriptions and selfdescribed RDM skill levels of the audience. It also alerts the presenters if there are any is sues that may need to be addressed at the beginning of the day. One misconception that has been identified through the pre-event survey was an expectation that we would be teaching librarians how to perform data analysis, which isn't part of the curricu- lum. By knowing this in advance, the presenters w e r e able to address it right a w a y and help to manage attendee expectations.

Figure 2: Perceived readiness to provide services: post-survey results. the event, and fu-

ture educational needs. To measure the impact of the RDM RoadShow and to assess the RDM knowledge, behaviors, and attitudes of liaison librarians and other participants, we developed a parallel research project. This consists of a pre-event survey and two post-event surveys at first and sixth month.
The pre-event survey also helps us determine if there are any data librarians attending who may be called upon to provide their own examples.

The two post-event surveys look for changes in knowledge, behavior, and attitudes and identify where the attendees feel 
more education is needed or desired. As all of the surveys are anonymous and presented in aggregate, we cannot tie specific change to one person over time. However, we anticipate that themes will emerge in the need for ongoing training and support. We also seek to identify the perceived effectiveness of the RDM RoadShow as a continuing education intervention.

\section{Future directions}

The RDM Road Show continues to grow into its second year, and the presenter team is hoping to add more trips and continue sharing the curriculum.

The preliminary first year results of the research project were presented at the Research Data Access and Preservation 2018 Summit in Chicago, and are currently being prepared for publication and sharing. ${ }^{3}$ Our intention is to continue gathering data from surveys for a five-year period and to make recommendations regarding the ongoing need for professional development training in RDM.

\section{Conclusion}

As academics across disciplines face increasing need for data management skills, librarians have an opportunity to apply their expertise in this additional realm. Through the ACRL RDM RoadShow, we hope more librarians may discover what aspects of RDM they already know and what possibilities exist as they contemplate integrating RDM and data information literacy into their practice.

\section{Notes}

1. Grant Wiggins and Jay McTighe, Understanding By Design. 2nd Expanded edition (Alexandria, VA: Association for Supervision \& Curriculum Development, 2005).

2. RDM RoadShow slides, handouts, and information on scheduling workshops, http://acrl.libguides.com/scholcomm/toolkit /RDMWorkshop.

3. Abigail Goben and Megan Sapp Nelson, "Engaging Liaisons thru Education: The First Year Results of the RoadShow" (Chicago, IL: Research Data and Preservation Summit 2018), https://osf.io/wtqu7/. n

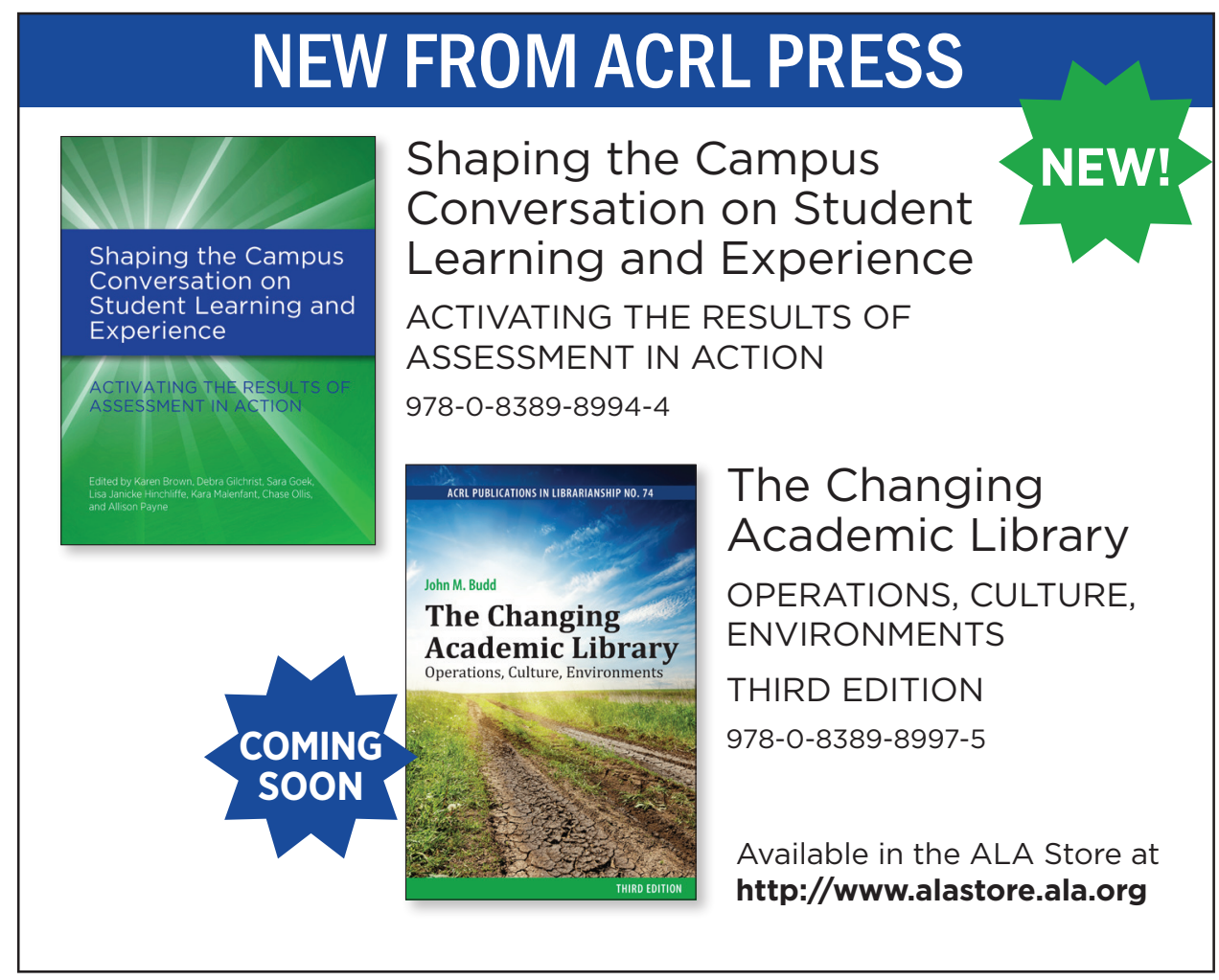

